\title{
Influence of Annealing Methods on the Magnetic Properties and Flexural Strength of Iron-OER Soft Magnetic Composites
}

\author{
Ling Xiao, ${ }^{1}$ Ming Li, ${ }^{1}$ Wenjie Cheng, ${ }^{1}$ Hongwei Fan, ${ }^{1}$ Xingzhou Chen, ${ }^{1}$ Yanhua Sun, \\ Chunhua Ding, ${ }^{2}$ and Lie $\mathbf{Y u}^{2}$ \\ ${ }^{1}$ Department of Basic Courses, Mechanics Research Center, Xian University of Science and Technology, No. 58, \\ Yanta Road, Xian, Shaanxi 710054, China \\ ${ }^{2}$ State Key Laboratory for Strength and Vibration of Mechanical Structures, Xian Jiaotong University, No. 28, \\ Xianning West Road, Xian, Shaanxi 710049, China
}

Correspondence should be addressed to Ling Xiao; xiaoling@xust.edu.cn

Received 19 January 2016; Revised 4 May 2016; Accepted 10 May 2016

Academic Editor: Pavel Lejcek

Copyright (C) 2016 Ling Xiao et al. This is an open access article distributed under the Creative Commons Attribution License, which permits unrestricted use, distribution, and reproduction in any medium, provided the original work is properly cited.

\begin{abstract}
This study aims at investigating high flexural strength iron-OER soft magnetic composites (SMCs) for active magnetic bearings (AMBs). Iron powders were firstly coated with oxide layer by the passivation process at room temperature. The effect of annealing methods on the static performance, magnetic properties, and flexural strength of SMCs was studied. The results showed that the significant improvements of permeability, magnetic loss, and flexural strength were presented by increasing the bonding number between iron surface and resin and using the two-step annealing method. In addition, the effect of pore shape and angle on the behavior of material fracture has been studied by FEM and the analysis was validated by experimental results.
\end{abstract}

\section{Introduction}

Soft magnetic composites (SMCs) present many new functions and unique properties such as low eddy current loss, high resistance, three-dimensional (3D) isotropy, and higher thermal stability. Therefore, the research of SMCs increases year by year and has gradually become a hotspot in the field of magnetic materials. Of course, till today, SMCs have been successfully applied to the field of nonconventional electrical machines only [1-3]. In such machines topologies, the complex shapes which cannot be manufactured by traditional silicon steels are required and eddy current loss has been effectively reduced. Although the application demands for SMCs used in active magnetic bearings (AMBs) are very similar to that in electrical machines, they need higher strength without weakening the magnetic properties for AMBs, especially for thrust disc which is subjected to a centrifugal force under high-speed rotation. So it is not feasible to use the existing SMCs instead of traditional carbon steel directly.

As the named publications mainly focus on the magnetic and electrical properties, there is a little experimental information about the strength of SMCs. To SMCs with inorganic coating, the flexural strength is performed [4-6] and the core loss of SMCs with a novel coating [5] is a little higher when the strength is $44 \mathrm{MPa}$. However, SMCs with organic coating have low eddy current loss [7], but there is a lack of studies on the flexural strength, which is influenced by many factors including coating amount, the annealing temperature and method, and the bond force between iron and OER. To enhance the experimental efficiency, some scholars have investigated that these performances can be adjusted by changing the ratio of inclusion and matrix [8] and preparation process [9-12]. And FEM analysis [12] indicates that the strength of resin layer is a quite important factor that affects strength and quality of SMCs. For the hydrophilic nature of ferromagnetic iron particles is incompatible with organic insulations, this requires the coupling agents, which can combine the inorganic and organic groups, to produce more hinge structures. Recently silane coupling agents are widely used to improve the adhesion between the metal and the polymer to increase the strength of the sample [13] and keep the insulating layer uniform. Because of the presence 
of organic materials, sintering cannot be used and residual stresses induced by cold work have deleterious effects on the magnetic performance of the core material. For this reason, annealing process for the elimination of residual stresses is essential and two-step annealing contributes to the growth of the magnetic domain and domain wall motion and then reduces the magnetic losses and improves the permeability of SMCs [11].

To obtain the good thermal stability and improve the flexural strength for SMCs, organic-silicon epoxy resin (OER) was chosen. For this class of materials such as ironOER SMCs, the optimum parameters including compaction pressure and annealing temperature have been discussed [12, 14] and the flexural strength has also improved accordingly. To improve the strength of whole composites even more without noticeable reduction in permeability, it needs to increase the numbers of sites for iron-to-OER bonding on the one hand and on the other hand eliminate residual stress and some internal defects by comparing different annealing methods.

The aim of this paper is to develop higher flexural strength iron-OER SMCs with better magnetic properties and to discuss the effects of interfacial adhesion between iron particles and OER and annealing method on magnetic properties and flexural strength of SMCs. For comparison purposes, two kinds of samples with the same composition are prepared by one- and two-step annealing, respectively. At last, to further explore the effect of annealing method on flexural strength for SMCs, finite element method (FEM) is used to analyze the damage process and fracture mechanism.

\section{Experimental Procedures}

2.1. Sample Preparation. Compared with traditional soft magnetic materials such as silicon steel and permalloy, iron powders provided by Fucheng Chemistry Factory were selected for the most prototypical soft magnetic material with very high saturation flux density $(2 \mathrm{~T})$. The purity of Fe was $98 \%$, containing $0.1 \%$ sulfuric acid insulation, $0.06 \% \mathrm{SO}_{4}$, $0.005 \% \mathrm{~N}, 0.005 \% \mathrm{Cu}$, and $0.03 \%$ water soluble. The iron powders were coated by organosilicon epoxy resin (OER, $0.6 \mathrm{wt} \%)$, silane coupling agent $\mathrm{KH}-550$, and curing agent $4,4^{\prime}$-diaminodiphenyl sulfone (DDS) (total $2.6 \mathrm{wt} \%$ ) which were supplied by Xi'an Resin Factory.

In order to increase the interfacial strength for organicinorganic composites, passivation method was used to generate $\mathrm{Fe}_{2} \mathrm{O}_{3}$ film on the surface of iron powders to increase bonding numbers with the coupling agent, and then a small amount of hydroxyls was produced after being dissolved by water [15].

The powder coating process was carried out as follows. The passivated iron powders and $\mathrm{KH}-550$ were mixed firstly in ethanol until the solution reaches the specified $\mathrm{pH}$ value. Secondly the cleaned powders were mixed with the OER in acetone by a spiral mixer for $1 \mathrm{hrs}$, and then we put DDS into the acetone solution and keep mixing until most of acetone is evaporated. At last, the coated powders were obtained and then heated at $150^{\circ} \mathrm{C}$ for $25 \mathrm{~min}$.

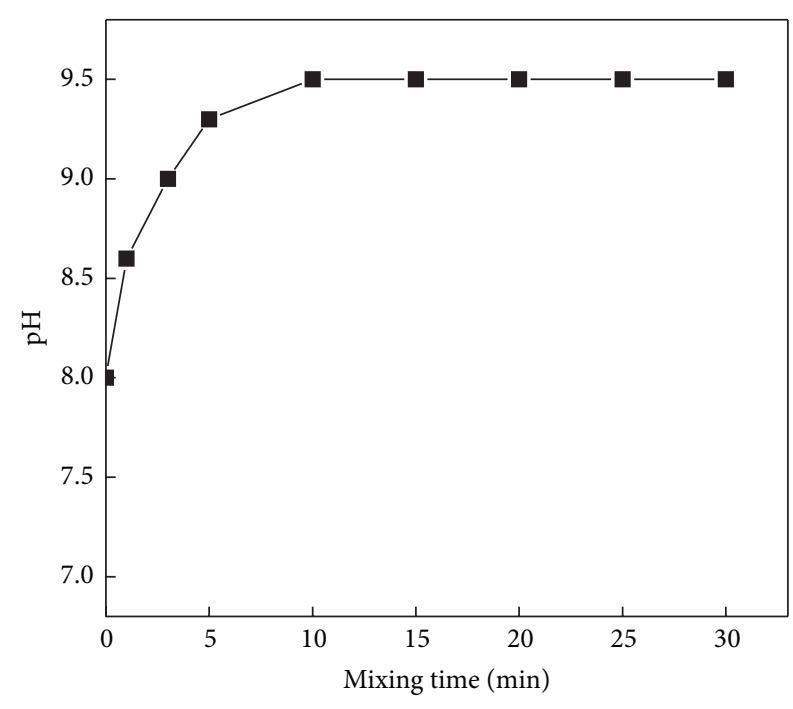

Figure 1: $\mathrm{pH}$ value as a function of mixing time.

The coated powders were cold-compacted at $800 \mathrm{MPa}$ in a cylindrical die with a diameter of $10 \mathrm{~mm}$ and $35 \mathrm{~mm}$ and then kept for 5 minutes. The glycerol was used as the lubricant. Finally, the specimens were subjected to one-step $\left(200^{\circ} \mathrm{C}\right.$ for $2 \mathrm{hrs})$ and two-step annealing $\left(130^{\circ} \mathrm{C}\right.$ for $1 \mathrm{hrs}$ and $200^{\circ} \mathrm{C}$ for $1 \mathrm{hrs}$ ) under vacuum condition, respectively.

2.2. Electrical, Magnetic, and Flexural Strength Characterization Conditions. The electrical resistivity was measured on the polished surface of cylindrical sample using fourpoint probe method (CMT-SR $1000 \mathrm{NV}$ ). Three readings were taken on each sample (diameter $10 \mathrm{~mm}$ ) and averaged. Magnetic properties and losses were tested by measuring system (D8 ADVANCE, Italy) for a ring-shaped core with an outer diameter of $35 \mathrm{~mm}$, inner diameter of $28 \mathrm{~mm}$, and height of $6 \mathrm{~mm}$. Complex permeability $\left(\mu^{\prime}\right.$ and $\left.\mu^{\prime \prime}\right)$ was calculated from $B_{m} \cos \delta /\left(\mu_{0} H_{m}\right)$ and $B_{m} \sin \delta /\left(\mu_{0} H_{m}\right)$, respectively, where $\delta$ is phase difference and can be obtained directly from the computer measurement and control system. Under the action of alternating magnetic field, each of the measured samples has both magnetic energy storage $\left(\mu^{\prime}\right)$ and consumption $\left(\mu^{\prime \prime}\right)$. The magnetic consumption described here is identified as hysteresis, eddy current, and residual losses. In the general case, for the resin-coated SMCs, the losses are mainly composed of eddy current and hysteresis losses. Flexural strength was measured by three-point bending method (Instron 5848, USA) for a bar specimen with the size $35 \mathrm{~mm} \times 4 \mathrm{~mm} \times 5 \mathrm{~mm}$.

\section{Results and Discussion}

3.1. Surface Analysis. The variation of $\mathrm{pH}$ value in mixing process is presented in Figure 1. The $\mathrm{pH}$ value first increases before $10 \mathrm{~min}$ and then is saturated to a final value of 9.5 for the formation of $\mathrm{NH}_{3}$ and $\mathrm{NaOH}$ [16]. Element distribution on surface of passivated irons is shown in Figure 2. It can be seen that the content of element oxygen is low and its distribution is uniform in general. 
TABLE 1: Basic performance through different annealing methods.

\begin{tabular}{lcc}
\hline Annealing method & Two-step annealing $\left(130^{\circ} \mathrm{C}\right.$ for $1 \mathrm{~h}+200^{\circ} \mathrm{C}$ for $\left.1 \mathrm{~h}\right)$ & One-step annealing $\left(200^{\circ} \mathrm{C}\right.$ for $\left.2 \mathrm{~h}\right)$ \\
\hline Density $\rho / \mathrm{g} / \mathrm{cm}^{3}$ & 5.95 & 5.63 \\
$\mathrm{HV}$ & 197.2 & 174.5 \\
$R / \mu \Omega \cdot \mathrm{m}$ & 668 & 675 \\
\hline
\end{tabular}
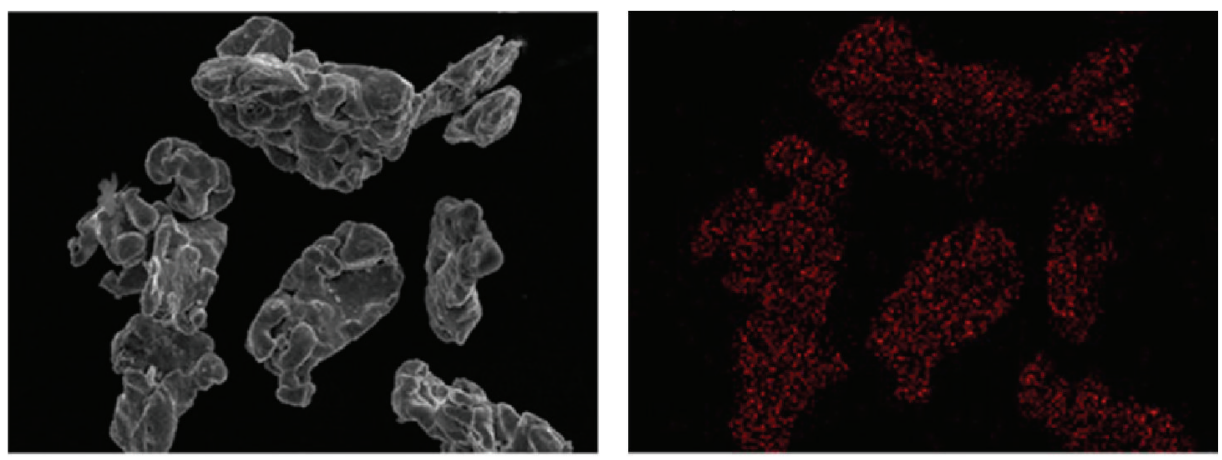

Fe Kal

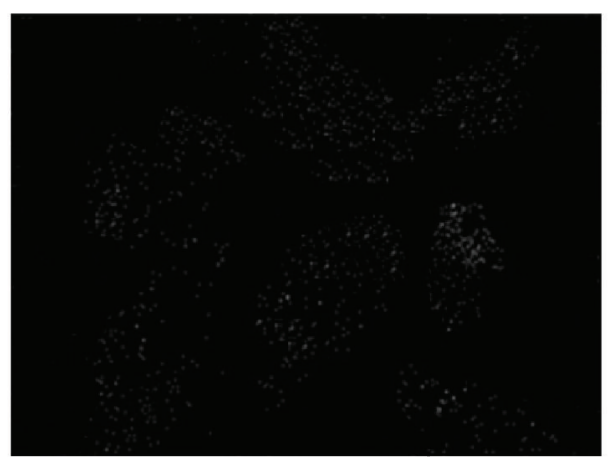

O Ka1

FIGURE 2: Element distribution on surface of passivated iron powders.

The FTIR spectrums for two different powders at $\mathrm{pH}$ value about 8 are presented in Figure 3. It can be noted that $-\mathrm{OH}$ groups at $3444 \mathrm{~cm}^{-1}$ (curve (a)) are generated on the surface of iron powders which indicate that the iron oxide shells have stronger absorption to the hydroxyl groups in the solution. However, the peak intensity in curve (b) corresponding to $-\mathrm{OH}$ groups at $3444 \mathrm{~cm}^{-1}$ decreases, which is attributed to the reaction between silanol groups of coupling agent and the $-\mathrm{OH}$ groups of passivated iron particles [17]. The peak at $2928 \mathrm{~cm}^{-1}$ is related to the stretching vibration of $\mathrm{C}-\mathrm{H}$ bond in propyl groups [18]. The peak at $1272 \mathrm{~cm}^{-1}$ is caused by $\mathrm{NH}_{2}$ deformation mode in coupling agent during the reaction with OER in Figure 4. The formations of $\mathrm{Si}-$ $\mathrm{O}-\mathrm{Fe}$ and $\mathrm{Si}-\mathrm{O}-\mathrm{Si}$ are observed at $1130 \mathrm{~cm}^{-1}$ and $1050 \mathrm{~cm}^{-1}$, respectively [19].

3.2. Basic Performance. Table 1 lists basic performance of each specimen through different annealing methods as measured in air atmosphere. All samples in Table 1 have the same

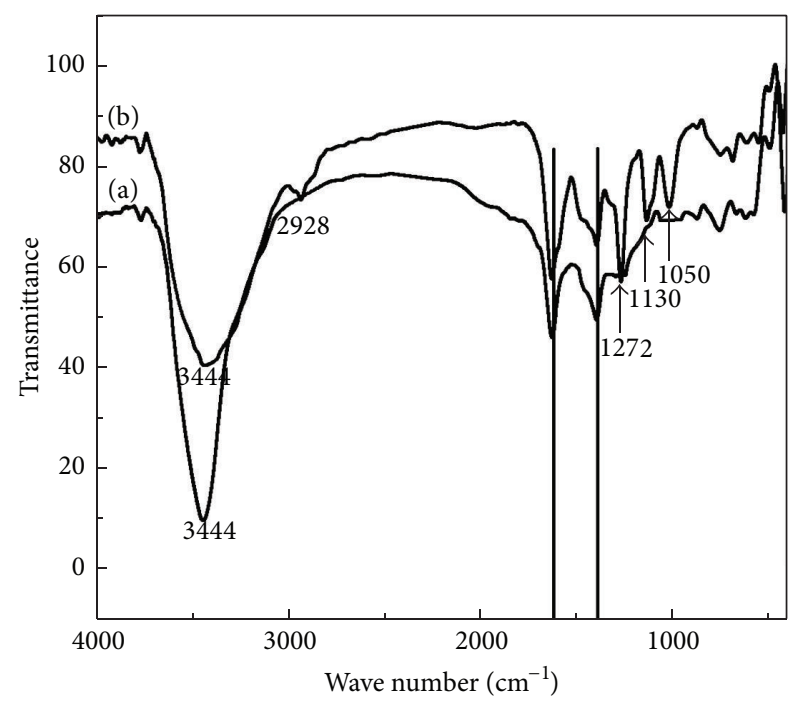

FIGURE 3: FTIR spectra (a) passivated powders and (b) insulated iron powders at $\mathrm{pH} 8$. 


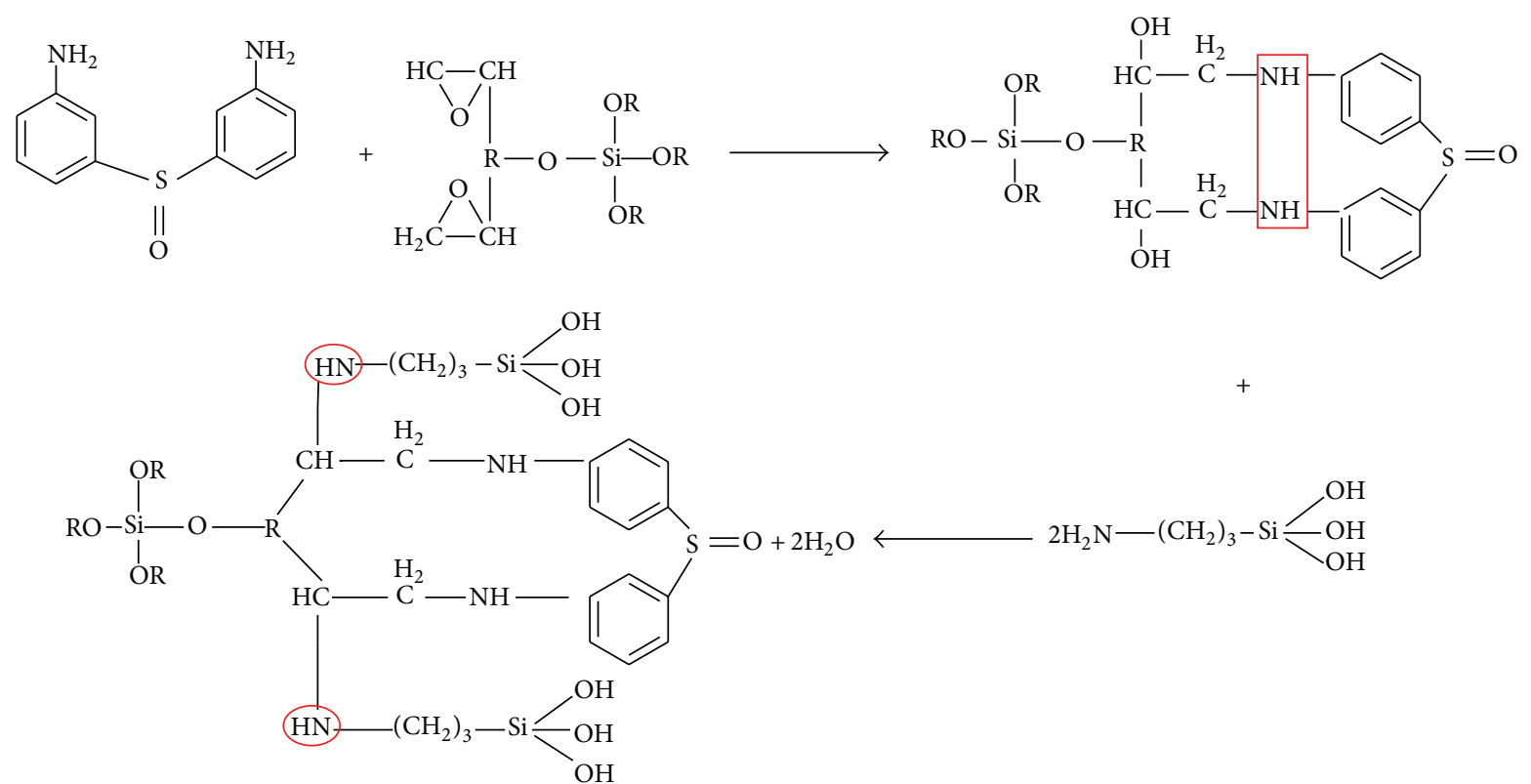

FIGURE 4: The structure of OER and its reaction mechanism with DDS and KH-550.

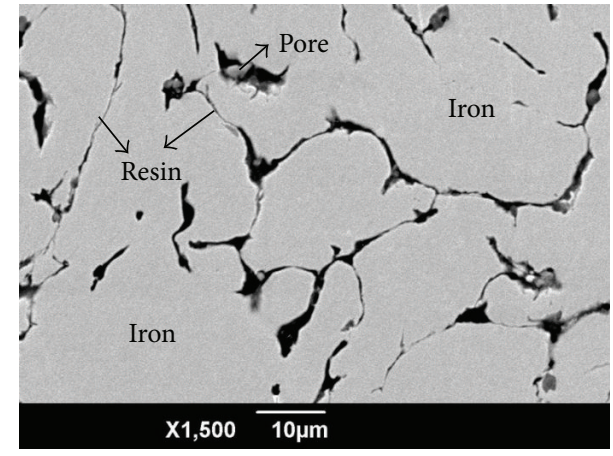

(a)

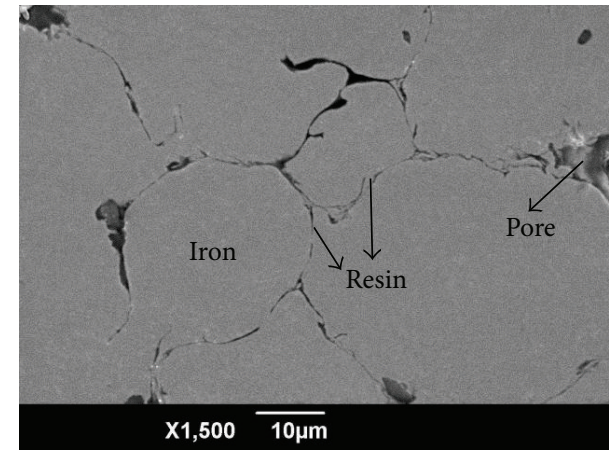

(b)

FIGURE 5: SEM micrograph of SMCs: (a) $200^{\circ} \mathrm{C}$ for $2 \mathrm{~h}$ and (b) $130^{\circ} \mathrm{C}$ for $1 \mathrm{~h}+200^{\circ} \mathrm{C}$ for $1 \mathrm{~h}$.

processing conditions except annealing treatment. As seen from this table, two-step annealing is helpful to improve the density and HV but goes against the resistivity. All of these three performance parameters are functions of particle size, powder composition, resin content, internal defects, and density (porosity). In Figure 5 there are lots of pores and the OER is nonuniform for the sample at one-step annealing. The corresponding EDS spectrums at resin, pore, and iron are shown in Figure 6. Comparing Figures 6(a) and 6(b), it is clear that Fe intensity decreases while Si intensity increases. However, the two-step annealing has fewer pores and denser structure. Therefore, it can be concluded that pores in SMCs are produced by the resin layer and annealing method has significant impact on the material structure and then influences the density and HV.

3.3. Magnetic Properties. The magnetic hysteresis loop for SMCs without initial magnetization at $50 \mathrm{~Hz}, 1 \mathrm{kHz}$, and $10 \mathrm{kHz}$ is shown in Figure 7. The calculated results indicate that the area encircled by hysteresis loop at one-step annealing is larger than that at two-step annealing in the same frequency condition and the area is growing with the increasing of frequency. During magnetization, the movement of magnetic domain walls is hindered by inhomogeneous structure in SMCs as shown in Figure 5, and the pinning effects are generated and enhanced, which need to consume more energy. Therefore, it increases the area of hysteresis loop. When the frequency increases from $50 \mathrm{~Hz}$ and $1 \mathrm{kHz}$, the change in the loop area is minor. When the frequency continues to rise to $10 \mathrm{kHz}$, the loop area and coercivity are at least twice as large as those in the previous two figures. It is attributed to eddy current and residual losses generated under the action of the alternating magnetic field. When frequency increases, the eddy current loss and its produced reverse magnetic field also increase at the same time, which have severely weakened the magnetic properties.

The real part of permeability $\left(\mu^{\prime}\right)$ as a function of frequency under the magnetic field intensity $0.7 \mathrm{~T}$ is shown 


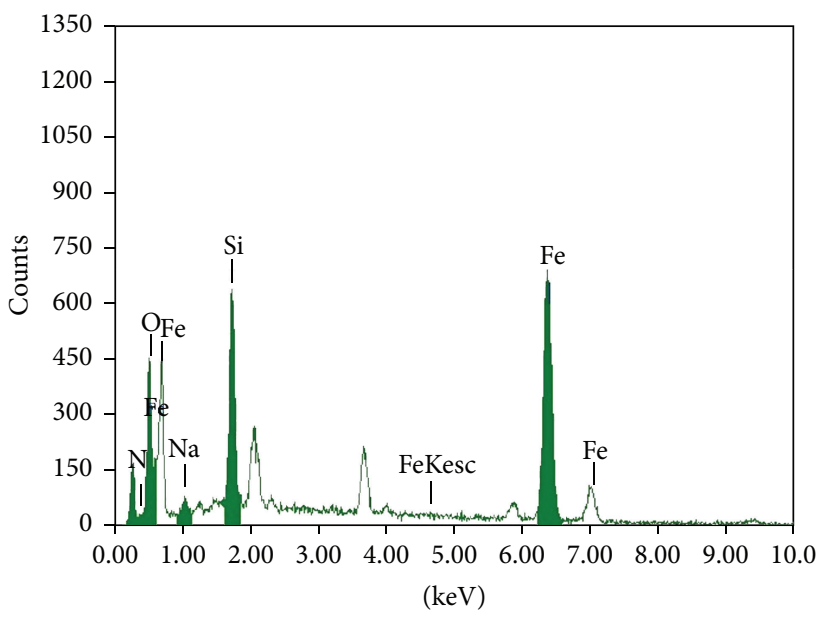

(a)

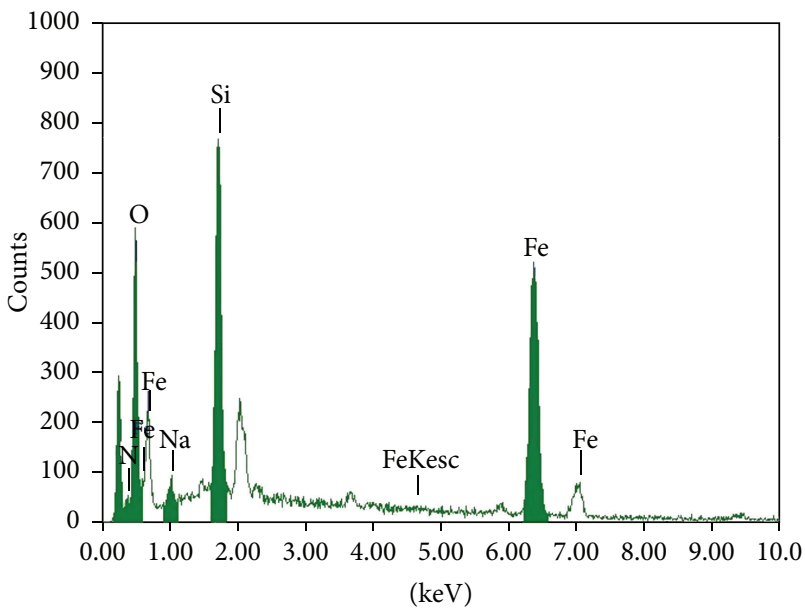

(b)

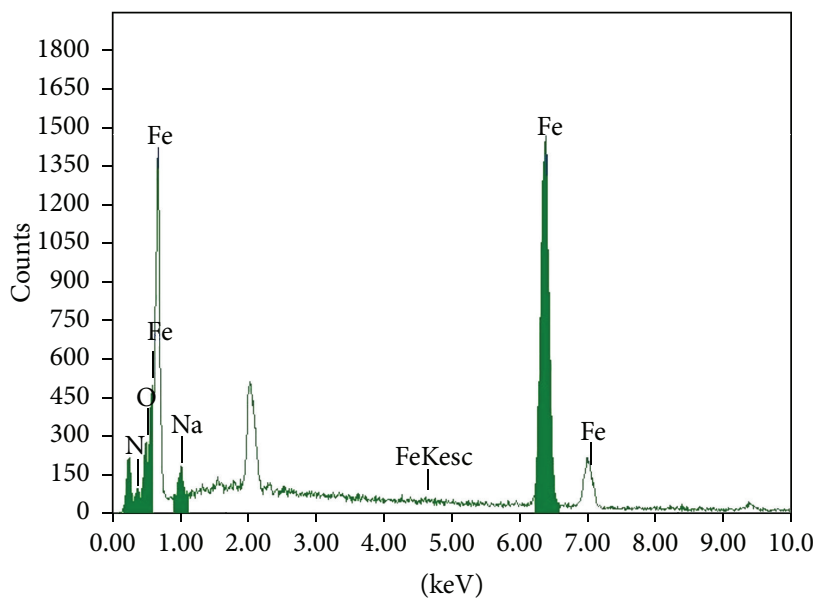

(c)

FIGURE 6: EDS spectrums for the sample at one-step annealing: (a) resin, (b) pore, and (c) iron.

in Figure 8(a). It can be seen that this part of permeability decreases slightly with increasing the frequency. And the real part at two-step annealing is approximately 18 percent higher than that at one-step annealing, because it strongly depends on the density, the number of pores, and defects of powder products under the same components. As the numbers of the pores in SMCs increase, the domain wall displacement and spin rotations are strongly blocked, which adversely affect the magnetic properties. Since the resin has the same permeability to vacuum and the permeability is usually much smaller than that of iron, it can be equivalent to the air gap (nonmagnetic phase) and nearly no flux lines enter into this region. The pores in SMCs structure act similarly to the nonmagnetic phase and weaken the magnetic properties.

The imaginary part of permeability $\left(\mu^{\prime \prime}\right)$ as a function of frequency for SMCs under the magnetic field intensity $0.7 \mathrm{~T}$ is shown in Figure 8(b). This part increases sharply after $1 \mathrm{kHz}$ and the sample at two-step annealing has a higher value. The reason for these behaviors could be an effect of the iron particles work hardened during compaction and compaction of incomplete coated particles to each other. The compaction always creates both some plastic deformation to increase the dislocation density in the iron powder particles and degradation of the insulation layer. The two-step annealing can reduce distortions within the particles, lower the residual stress effectively, and then improve the magnetic properties significantly for SMCs. For the sample at one-step annealing, more pores and less volume fraction of magnetic particles reduce magnetic loss and directly lower the imaginary part.

3.4. Flexural Strength. Due to the immiscibility of iron powders and resin and different thermal expansion coefficients for both, it leads to the increase of pores in SMCs after annealing and cooling to ambient temperature. Pores in SMCs act as stress concentration centers and the load-bearing area is reduced. To improve strength of whole material, it needs to reduce the numbers of pores on the one hand and on the other hand improve the adhesion strength between iron and OER by the passivation treatment when heated in vacuum. Effect of annealing method on the porosity and flexural strength is presented in Table 2. It can be seen that the porosity at two-step annealing is lower and the corresponding flexural 
TABLE 2: Effect of annealing method on the porosity and flexural strength.

\begin{tabular}{lcr}
\hline Annealing method & Two-step annealing $\left(130^{\circ} \mathrm{C} 1 \mathrm{~h}+200^{\circ} \mathrm{C}\right.$ for $\left.1 \mathrm{~h}\right)$ & One-step annealing $\left(200^{\circ} \mathrm{C}\right.$ for $\left.2 \mathrm{~h}\right)$ \\
\hline Porosity & $4.8 \%$ & $13.4 \%$ \\
Flexural strength/MPa & 44.52 & 40.36 \\
\hline
\end{tabular}
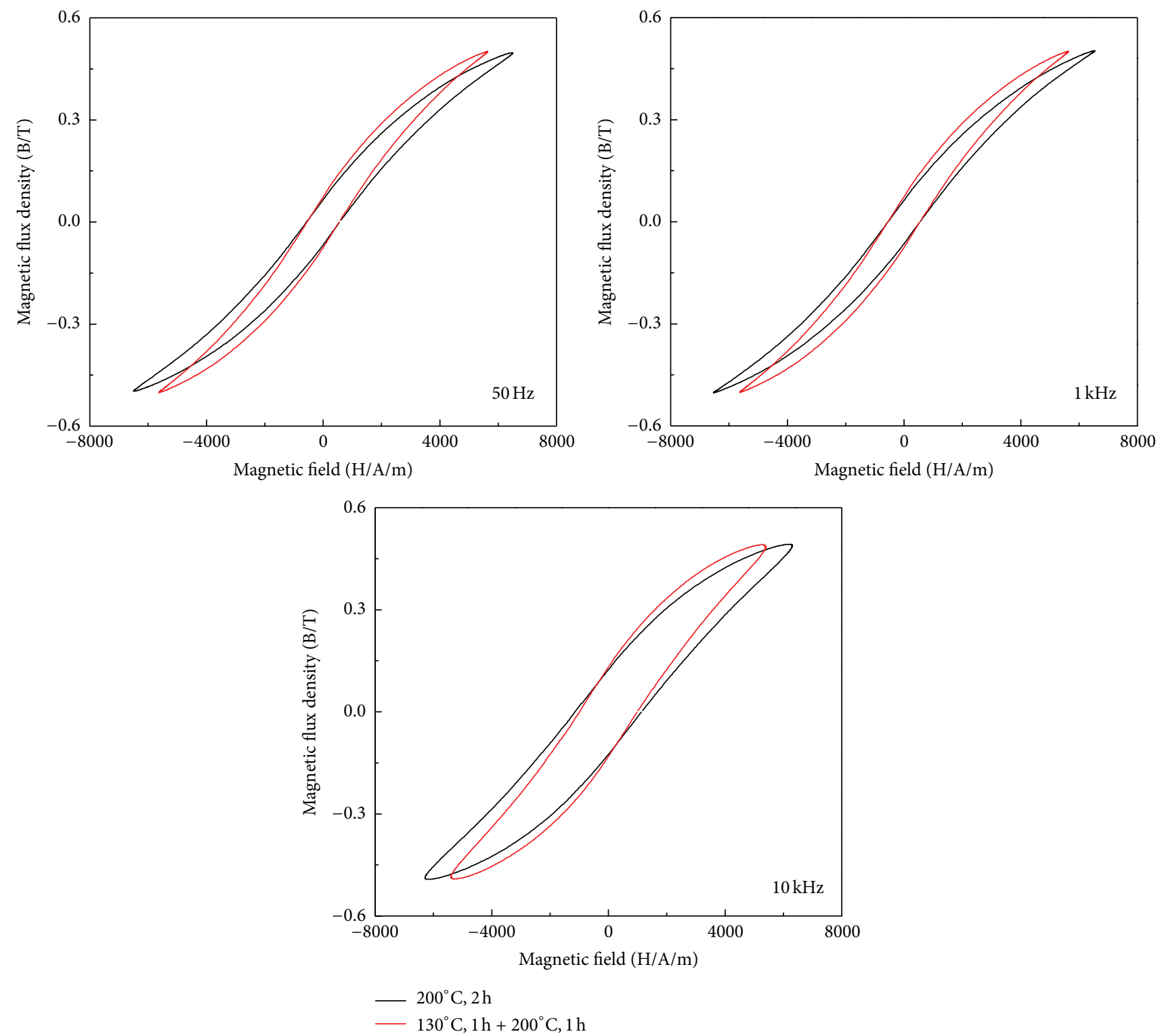

FIGURE 7: Magnetic hysteresis loops of SMCs at different frequencies.

strength is higher than that at one-step annealing. This is because the residual stresses can be effectively minimized by thermal motion of the atoms for the sample at two-step annealing, and then high uniformity insulating film and lowvolume fraction of pores are provided.

The iron-resin SMCs are mainly composed of iron powders, resin, pores, and defects. Under external force, some microcracks are produced at the interface between resin and iron particles as shown in Figure 9. From this figure, it can be seen that the volume of pores is smaller and the microcracks are fewer and finer for the sample at two-step annealing comparing to that at one-step annealing. Most of these microcracks are distributed at the acute angles of pores (D) and some of them are connected with two adjacent pores (such as (A) and (B)). In Figure 9, because of irregular iron powders, sharp corners, and big curvature, it is more likely to form tip pores to exacerbate stress concentration and accelerate the formation and development process for these initial cracks under a concentrated load. When cracks propagate to the stress interface under an increasing load, 


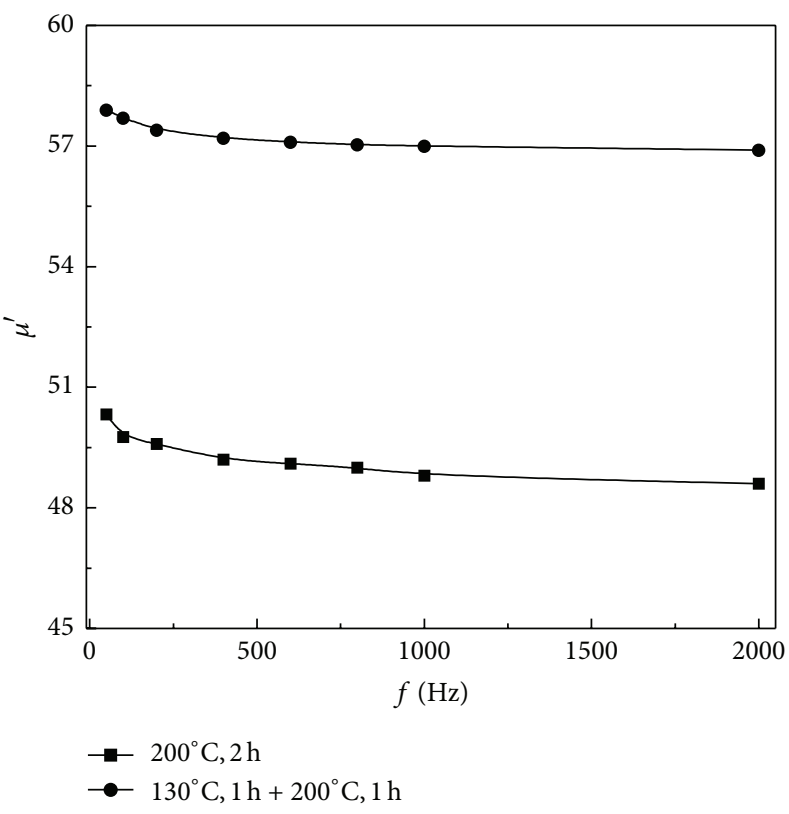

(a)

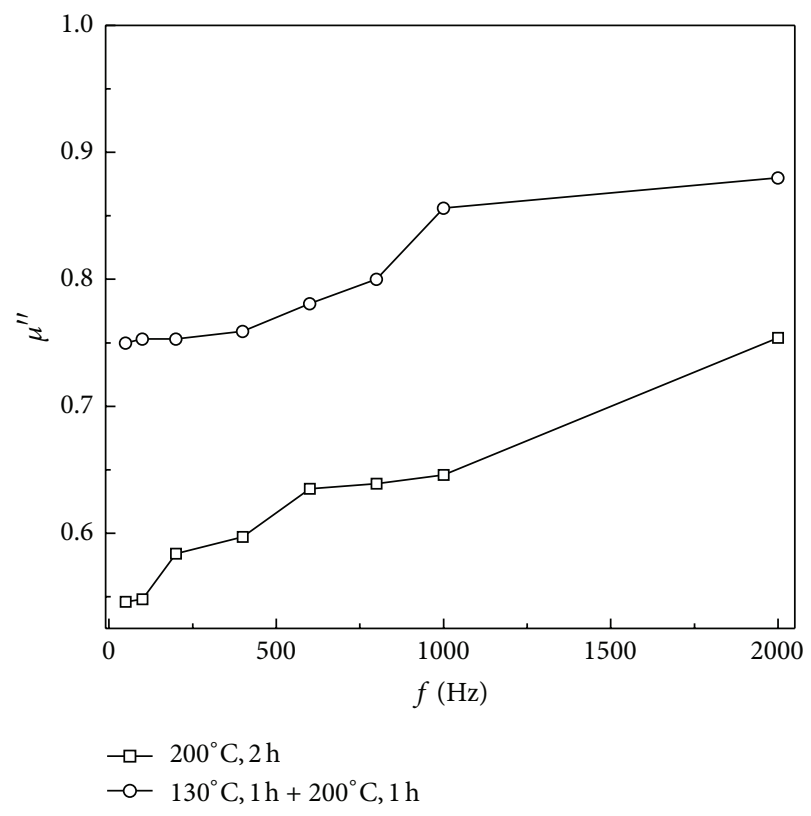

(b)

FIgURE 8: Complex permeability as a function of frequency at $0.7 \mathrm{~T}$.

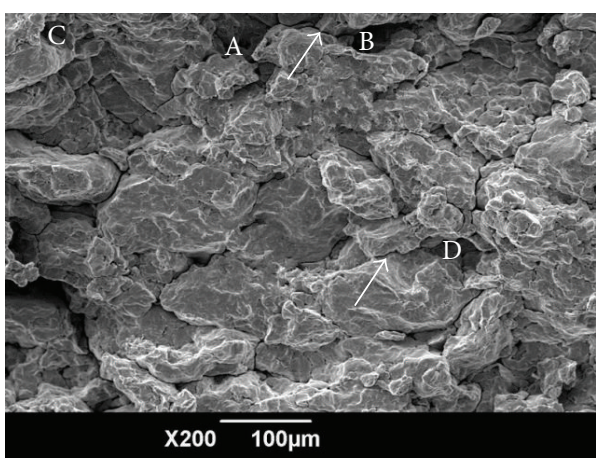

(a)

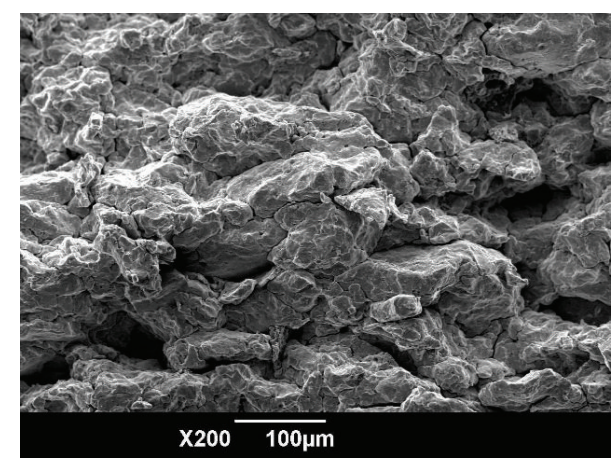

(b)

Figure 9: Fracture surfaces of SMCs at different annealing methods: (a) $200^{\circ} \mathrm{C}$ for $2 \mathrm{~h}$ and (b) $130^{\circ} \mathrm{C}$ for $1 \mathrm{~h}+200^{\circ} \mathrm{C}$ for $1 \mathrm{~h}$.

the stress is freed and corresponding bending deformation is generated.

For further analysis of the effect of pores with different shapes on the material strength, finite element method (FEM) is used to analyze the damage process for SMCs. Although flake-shaped electrolytic iron powder [20] and sphericalshaped atomized powder in Figure 10 are widely used in SMCs materials, the shape of iron powder resembles hexagon when the irregular powders are compacted together. In previous research, the experimental values for magnetic properties have a good agreement with the calculated ones between the circular and hexagon models; so in this paper those two models with different pores are also required as shown in Figure 11. In these two models, both of the hexagonal side length and the diameter of the circle are $100 \mu \mathrm{m}$ and the smallest coating thickness is $2 \mu \mathrm{m}$. The porosities are calculated by the theoretical method [8], which is determined by resin content. Material properties are then manually assigned to each region. The discretization of the three models is performed by an automatic meshing algorithm. In order to improve computing precision, finer mesh is also taken into account on the very thin insulating layer and the pores as shown in Figure 12. The mesh examples shown in Figure 3 have 9885 (a), 23757 (b), and 5843 (c) nodes, respectively.

The load, which is equal to the experiment result for SMCs with $99 \mathrm{wt} \% \mathrm{Fe}$, is applied on the center of top lines, which narrows the insulating layer on the upper half, while widening the layer on the lower half in Figure 13. The results show that the strain of insulating layer is much larger than that of the iron and the maximum strain is found to occur near the thinnest insulating layer. The strain in the model with acute pores in Figure 13(b) is larger than that in Figure 13(a) with obtuse one. Comparing the two hexagon models with and without pores [12], we can see that the model with pores 

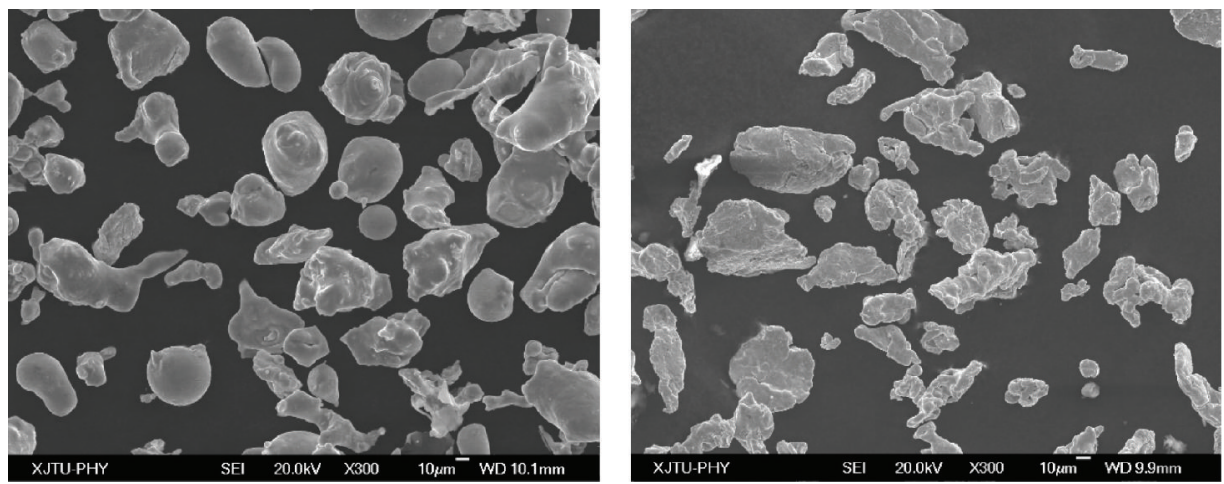

FIGURE 10: SEM micrograph of iron powders.

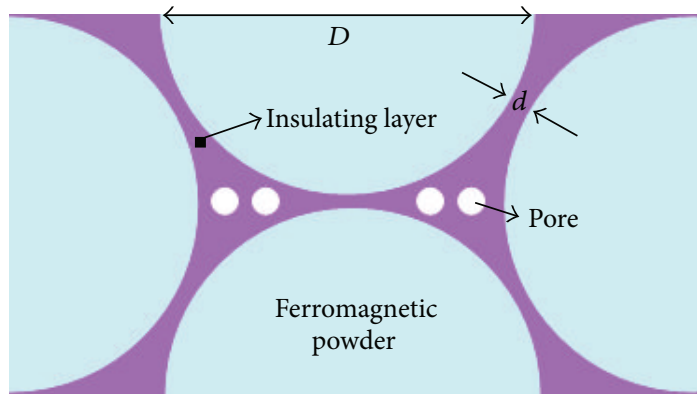

(a)

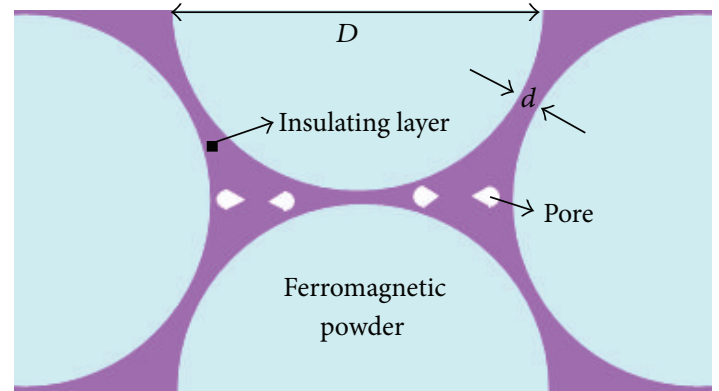

(b)

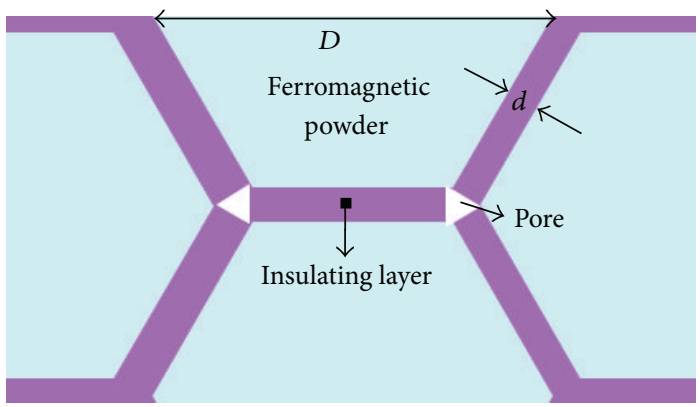

(c)

FIGURE 11: Simplified models: (a) circular pores; (b) circular pores with acute angle; (c) hexagon pores with acute angle.

has larger strain and the maximum strain drops almost 48 percent between two models. Magnifications of displacement vector sum for three models are shown in Figure 14. When the load is applied on the model with an obtuse pore, there is no crack generated (see Figure 14(a)) and only deformation occurred, which are consistent with Figure 9 (C). When the load is applied on the model with an acute pore, crack is generated and propagates along this angle and interface between resin and iron particles (see Figures 14(c) and 9 (D)). Especially when the acute angles of the two adjacent pores have the opposite direction and meet face to face, it can be seen from the different displacement in a vertical line that crack is generated as shown in Figure 14(b), which is corresponding to Figure 9 (A and B).

Through the above analysis, it can be concluded that the pore in SMCs plays a vital role in mechanical strength and the crack propagation depends upon the applied load as well as the shape of pores. Regarding one-step annealing sample, there is not enough time to eliminate residual stress when the temperature reaches value as high as $200^{\circ} \mathrm{C}$ and some acute pores are generated, which ultimately lead to lower strength.

\section{Conclusion}

In this work, high flexural strength iron-OER SMCs with better magnetic properties for active magnetic bearings (AMBs) were prepared successfully. The effect of interfacial adhesion between iron particles and OER and annealing methods on the static performance, magnetic properties, and flexural strength was investigated. The results can be concluded as follows:

(1) Coating of the iron particles was carried out successfully by passivation and modification with KH-550. EDS, SEM, and FTIR spectra proved that the iron 


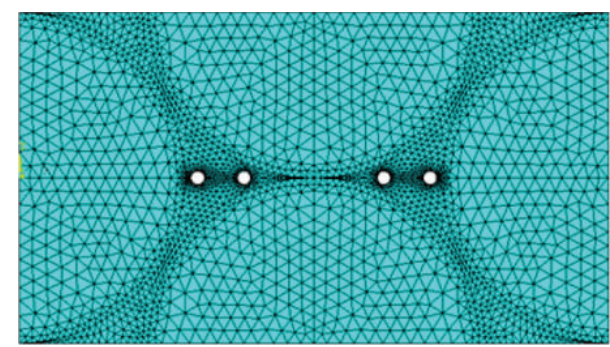

(a)

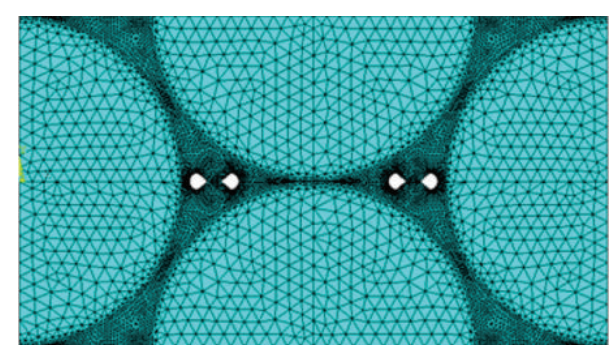

(b)

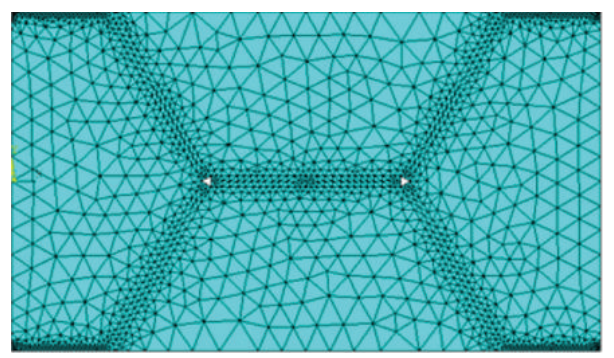

(c)

FIGURE 12: Mesh of models in FE environment: (a) circular pores; (b) circular pores with acute angle; (c) hexagon pores with acute angle.
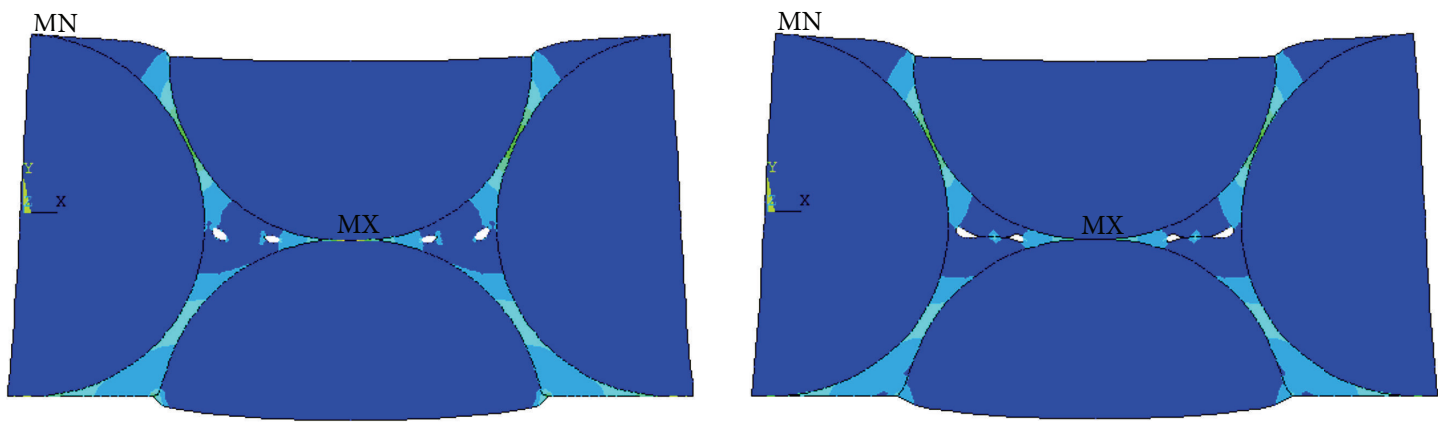

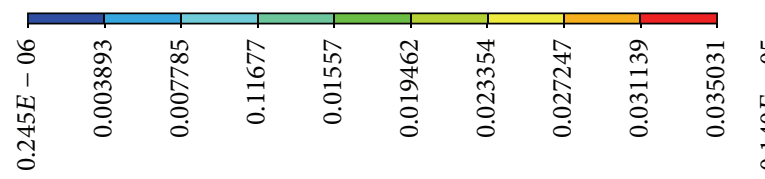

(a)

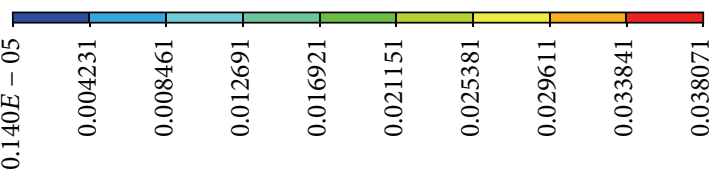

(b)

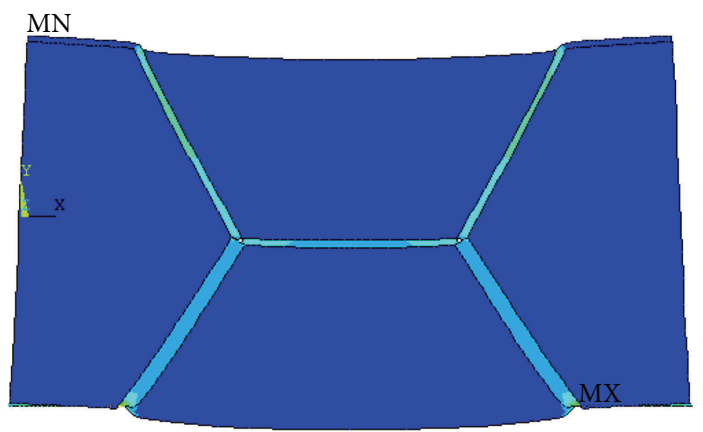

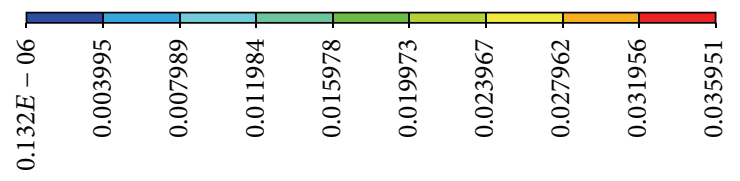

(c)

FIGURE 13: Total mechanical strain intensity for three models: (a) circular pores; (b) circular pores with acute angle; (c) hexagon pores with acute angle. 

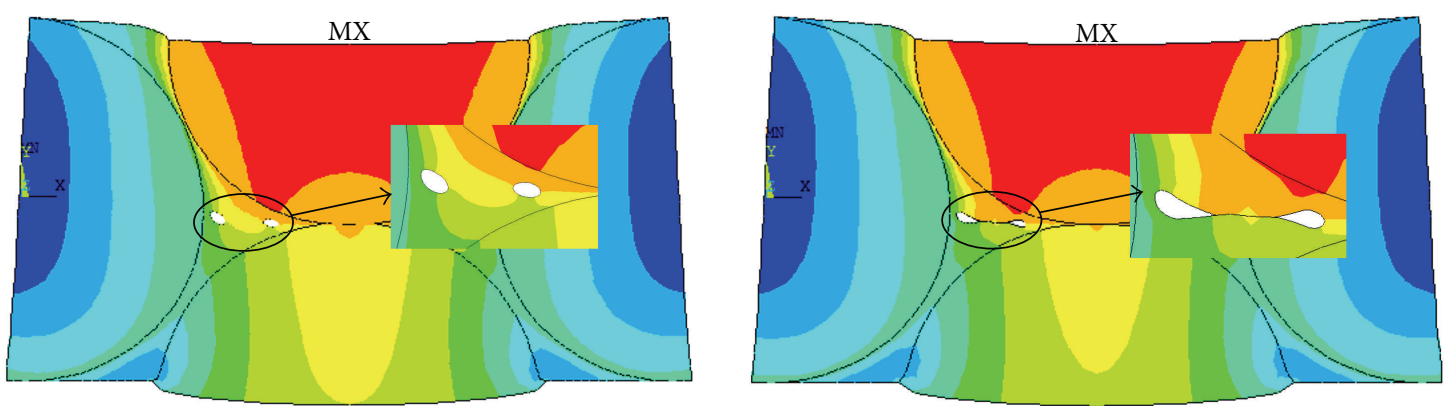

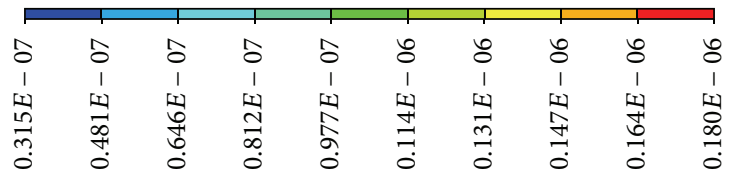

(a)

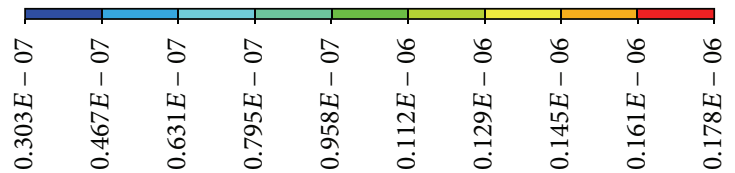

(b)

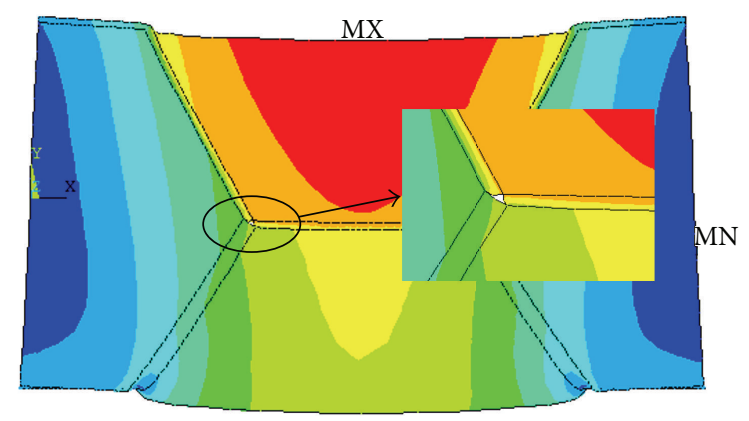

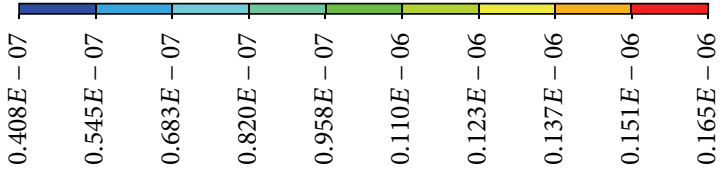

(c)

FIGURE 14: Displacement vector sum for three models: (a) circular pores; (b) circular pores with acute angle; (c) hexagon pores with acute angle.

particles were uniformly covered with oxide layers and OER insulation.

(2) Two kinds of annealing methods have different effects on the physical and magnetic properties for the samples. Two-step annealing method improved the density, HV, and permeability of SMCs, while decreasing the magnetic loss because of the low hysteresis loss and resistivity for SMCs.

(3) The increase of the bonding number between iron surface and resin by passivation method and the choice of two-step annealing method resulted in higher flexural strength. The crack propagation analysis (FEM) shows that the flexural strength is related to the applied load as well as the shape and angle of pores.

\section{Competing Interests}

The authors declare that they have no competing interests.

\section{Acknowledgments}

The work described in this paper was supported by the National Natural Science Foundation of China (Grant nos. 11502196, 51275386, and 11372245), Shaanxi Provincial Education Department Fund (Grant no. 15JK1483), and China Postdoctoral Science Foundation (Grant no. 2015M580865).

\section{References}

[1] A. Hamler, V. Goričan, B. Šuštaršič, and A. Sirc, "The use of soft magnetic composite materials in synchronous electric motor," Journal of Magnetism and Magnetic Materials, vol. 304, no. 2, pp. e816-e819, 2006.

[2] L. O. Hultman and A. G. Jack, "Soft magnetic compositesmaterials and applications," in Proceedings of the IEEE International Electric Machines and Drives Conference (IEMDC '03), pp. 516-522, June 2003.

[3] A. Jack, B. Mecrow, P. Dickinson et al., "Design and testing of a universal motor using a soft magnetic composite stator," in Proceedings of the Conference Record of the 2000 IEEE Industry Applications Conference, pp. 46-50, IEEE, 2000. 
[4] R. Bidulský, J. Bidulská, T. Kvačkaj, and M. Actis Grande, "Analysis of the fracture surfaces of new development insulated iron powder compounds," Acta Physica Polonica A, vol. 126, no. 1, pp. 154-155, 2014.

[5] L. Frayman, S. Quinn, R. Quinn, D. Green, and F. Hanejko, "Advanced soft magnetic composite materials for AC applications with reduced iron losses," Powder Metallurgy, vol. 58, no. 5, pp. 335-338, 2015.

[6] R. Bidulský, J. Bidulská, R. De Oro et al., "Interparticle neck connections in innovative insulated iron powder compounds," Acta Physica Polonica A, vol. 128, no. 4, pp. 647-650, 2015.

[7] A. H. Taghvaei, H. Shokrollahi, and K. Janghorban, "Magnetic and structural properties of iron phosphate-phenolic soft magnetic composites," Journal of Magnetism and Magnetic Materials, vol. 321, no. 23, pp. 3926-3932, 2009.

[8] L. Xiao, Y. H. Sun, C. H. Ding, L. Yang, and L. Yu, "Influence of the component size ratio on densification and magnetic property of soft magnetic composites," International Journal of Applied Electromagnetics and Mechanics, vol. 39, no. 1-4, pp. 547-553, 2012.

[9] H. Shokrollahi and K. Janghorban, "The effect of compaction parameters and particle size on magnetic properties of ironbased alloys used in soft magnetic composites," Materials Science and Engineering B: Solid-State Materials for Advanced Technology, vol. 134, no. 1, pp. 41-43, 2006.

[10] H. Shokrollahi and K. Janghorban, "Effect of warm compaction on the magnetic and electrical properties of Fe-based soft magnetic composites," Journal of Magnetism and Magnetic Materials, vol. 313, no. 1, pp. 182-186, 2007.

[11] H. Shokrollahi and K. Janghorban, "Different annealing treatments for improvement of magnetic and electrical properties of soft magnetic composites," Journal of Magnetism and Magnetic Materials, vol. 317, no. 1-2, pp. 61-67, 2007.

[12] L. Xiao, Y. Sun, C. Ding, L. Yang, and L. Yu, "Annealing effects on magnetic properties and strength of organic-silicon epoxy resin-coated soft magnetic composites," Proceedings of the Institution of Mechanical Engineers, Part C: Journal of Mechanical Engineering Science, vol. 228, no. 12, pp. 2049-2058, 2014.

[13] M. Iijima, M. Tsukada, and H. Kamiya, "Effect of particle size on surface modification of silica nanoparticles by using silane coupling agents and their dispersion stability in methylethylketone," Journal of Colloid and Interface Science, vol. 307, no. 2, pp. 418-424, 2007.

[14] L. Xiao, Y. H. Sun, and L. Yu, "The effect of compaction parameters and dielectric composition on properties of soft magnetic composites," Journal of Physics: Conference Series, vol. 303, no. 1, Article ID 012086, 2011.

[15] A. H. Taghvaei, H. Shokrollahi, A. Ebrahimi, and K. Janghorban, "Soft magnetic composites of iron-phenolic and the influence of silane coupling agent on the magnetic properties," Materials Chemistry and Physics, vol. 116, no. 1, pp. 247-253, 2009.

[16] D. M. Brasher and C. P. De, "Passivation of iron by chromate solutions," Nature, vol. 180, no. 4575, pp. 28-29, 1957.

[17] J. Xu and C. P. Wong, "Characterization and properties of an organic-inorganic dielectric nanocomposite for embedded decoupling capacitor applications," Composites Part A: Applied Science and Manufacturing, vol. 38, no. 1, pp. 13-19, 2007.

[18] E. Ukaji, T. Furusawa, M. Sato, and N. Suzuki, "The effect of surface modification with silane coupling agent on suppressing the photo-catalytic activity of fine $\mathrm{TiO}_{2}$ particles as inorganic UV filter," Applied Surface Science, vol. 254, no. 2, pp. 563-569, 2007.

[19] H. Iida, T. Nakanishi, and T. Osaka, "Surface modification of $\gamma$ - $\mathrm{Fe}_{2} \mathrm{O}_{3}$ nanoparticles with aminopropylsilyl groups and interparticle linkage with $\alpha, \omega$-dicarboxylic acids," Electrochimica Acta, vol. 51, no. 5, pp. 855-859, 2005.

[20] M. Streckova, R. Bures, M. Faberova, L. Medvecky, J. Fuzer, and P. Kollar, "A comparison of soft magnetic composites designed from different ferromagnetic powders and phenolic resins," Chinese Journal of Chemical Engineering, vol. 23, no. 4, pp. 736743,2015 . 

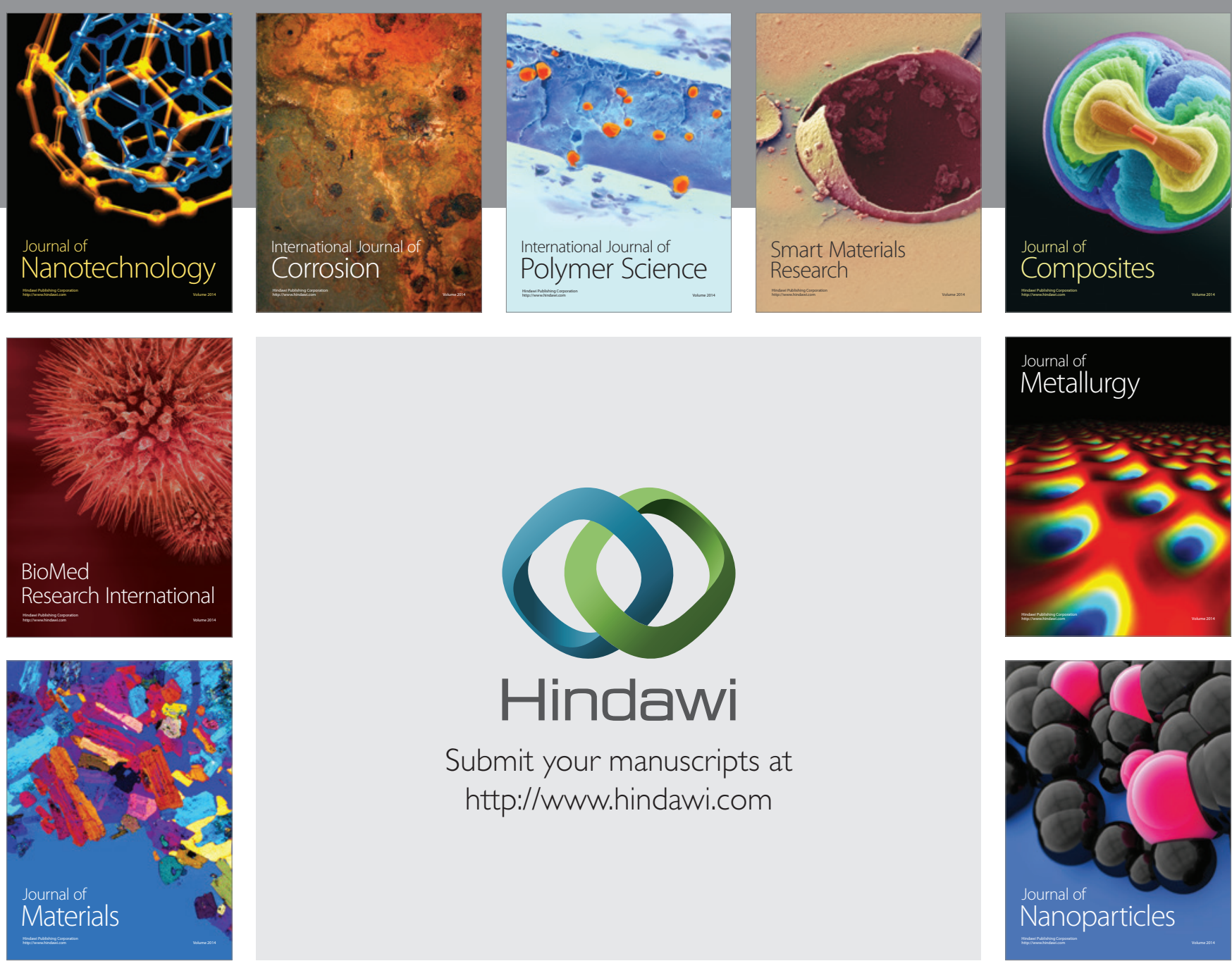

\section{Hindawi}

Submit your manuscripts at

http://www.hindawi.com

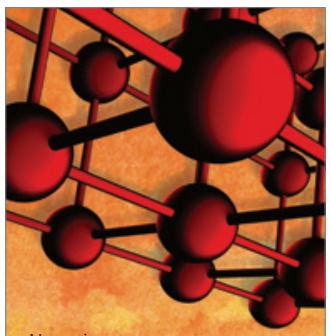

Materials Science and Engineering
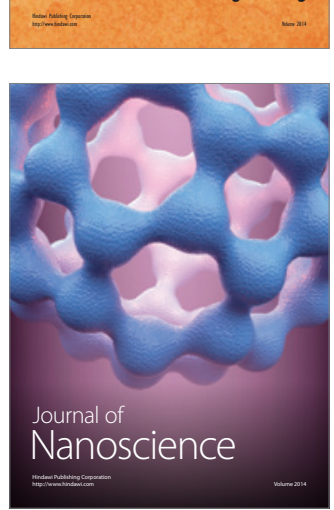
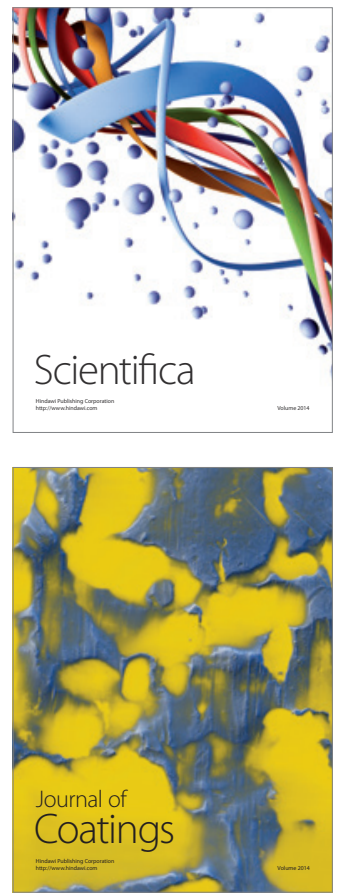
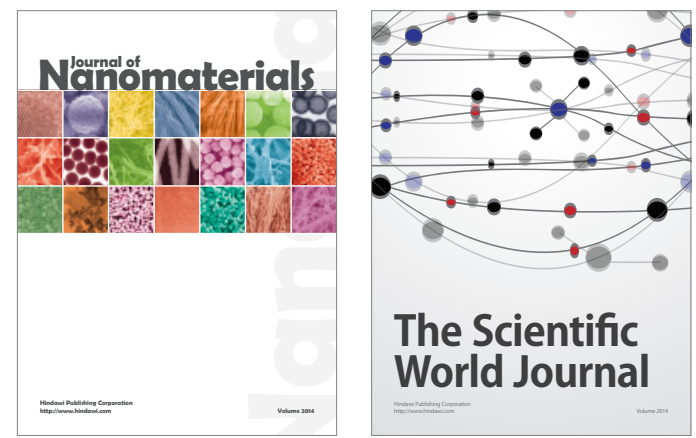

The Scientific World Journal
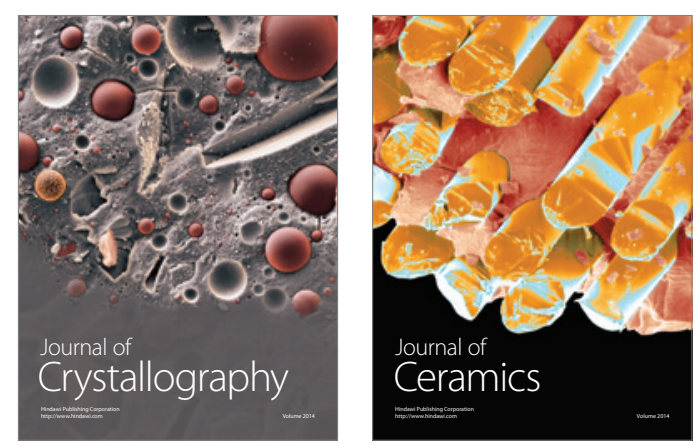
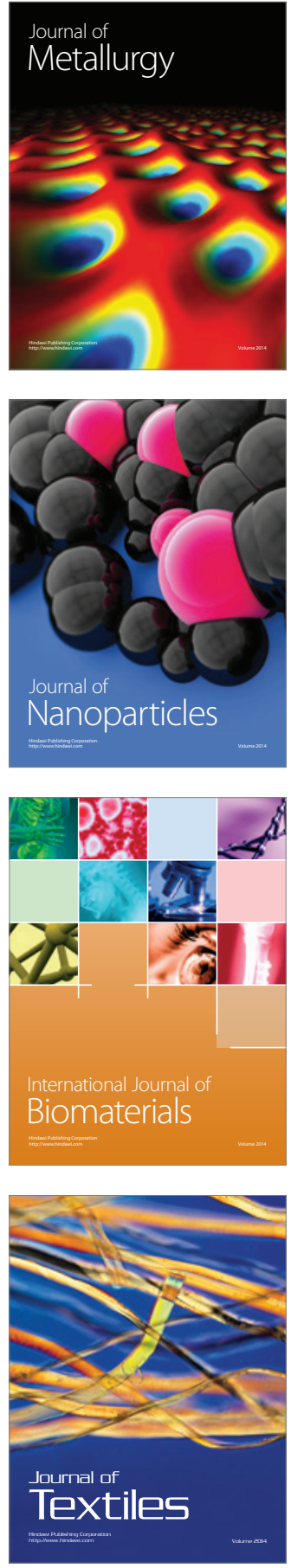